\title{
Regeneration Research in the Soviet Union
}

\author{
BRUCE M. CARLSON 1 \\ Department of Anatomy, University of Michigan, Ann Arbor, Michigan
}

\begin{abstract}
Over the past 20 years Soviet research in regeneration has undergone a shift in emphasis from work on amphibians to mammals. In that period several distinct schools of thought have arisen, and often there has been considerable controversy as to the nature of certain regenerative processes. At present most mammalian tissues and organs are being studied with respect to natural regenerative capacity and means of stimulating further regeneration. The most striking results have been obtained in the areas of muscle and bone regeneration. Progress in other areas has been less spectacular. Considerable effort has been put into devising means of regenerating functional tissue from pathologically changed or irradiated organs. The field of regeneration research in the Soviet Union is quite highly organized and includes a relatively laxge number of workers. Progress has, to some extent, been impeded by shortages of equipment and biochemical preparations.
\end{abstract}

For the past 20 years, the development of regeneration research in the Soviet Union has followed a course different from that in other countries. During a recent exchange visit to the U.S.S.R., it became evident to me that much of the Soviet work in this field is not well known by members of the Western scientific community. The following report will present a general outline of the historical development and current areas of emphasis in Soviet work on vertebrate regeneration.

\section{HISTORICAL DEVELOPMENT}

Before the 1930's, Soviet work on regeneration constituted a rather small portion of the total biological research effort, with scattered publications of investigations carried out on vertebrate forms and a lesser number of studies conducted on invertebrates. The rise of the strong school in developmental mechanics under the leadership of D. P. Filatov during the 1920's and 1930's furnished the initial impetus for the active program of regeneration currently underway (Polezhaev, '46a). A number of the leaders in this field today were either trained as experimental embryologists under Filatov or were, at least, considerably influenced by his work.

The theoretical basis for many of the investigations taking place during this period was closely allied to the thinking in experimental embryology at that time, and starting in the early 1930's there appeared a large number of papers on the determina- tion, potencies and morphogenesis of the regeneration blastema (Polezhaev, '45; Vorontsova, ' $49^{2}$; Vorontsova and Liosner, '60) as well as a series of investigations concerned with the role of inductive processes taking place in regeneration and supernumerary limb formation (Fedotov, '46; Nassonov, '41). Of the Russian research during this period, the work of $\mathrm{L}$. V. Polezhaev exerted the greatest influence upon Western biologists. Perhaps the most important contributions were his demonstration that amputated limbs of post-metamorphic frogs can be stimulated to regenerate by severely traumatizing the limb stumps (Polezhaev, '46b) and his early recognition of the importance of epithelialmesodermal interrelationships in amphibian limb regeneration (Polezaiev and Faworina, '35). During this period several investigators attempted to delineate the role of individual tissue components of limb and tail stumps with respect to their contribution to and morphogenetic control over the regenerate (Vorontsova and Liosner '60, pp. 39-361). One of the most significant contributions was the demonstration by Umanski ('37) that x-radiated axolotl limbs provided with normal skin produce regenerates whose form reflects the origin of the skin.

1 The author spent the period from December 1965 to May 1966 in the Soviet Union under the auspices of the exchange program between the Academies of Sciences of the USA and USSR.

2 This book contains an almost complete bibliography of Soviet regeneration work before 1949. 
The post war period witnessed a profound change in both the direction and relative prominence of work in this field. In the late 1940's both St ditsky ('48) and Vorontsova ('49, '53) po ited out that in higher vertebrate forr, especially mammals, restorative proce ses do take place in many tissues and or ans, but that the mechanisms underlying these events are not always those which rad been included in classical schemes of regeneration. Following these repor.; emphasis rather quickly changed from research on amphibians to investigations on birds and mammals.

In this troubled era of Soviet biology, much of the work in the field of regeneration was, at least in published form, relatively free from many of the pressures brought to bear upon certain other biological disciplines, but nevertheless condemnations of then unpopular Western scientific doctrines such as Mendelism-Morganism-Weissmanism dutifully appeared in introductions to many of the research reports of this period (Khruschev, '54).

During this period, however, greater attention was focussed upon the influence of microenvironmental conditions (uslovie), both natural and artifically applied, upon the course of regeneration. This emphasis has continued to the present day and has in a number of instances been a fruitful approach to the problem of stimulating regeneration. In the past 15 years greatest emphasis has been placed upon the study of reparative phenomena in higher vertebrates. These studies have included most of the major tissue and organ systems of the body and have been primarily concerned with delineations of their normal regenerative capacities, the mechanisms underlying these events and possibilities of stimulating further regeneration in tissues or organs with poor natural regenerative capacities.

\section{CONTROVERSIAL THEORIES}

In order to interpret meaningfully much of the Soviet literature on regeneration, it is necessary to recognize the theoretical background upon which the work was based. This holds true with respect to not only the proposed mechanisms of certain regenerative processes, but also the proc- esses which are considered to be regenerative.

Since the war, research in vertebrate regeneration has been largely dominated by four major schools of thought, headed by L. F. Polezhaev, A. N. Studitsky, L. D. Liosner and A. A. Voitkevich. Each is occupied with different problems, but their general theories often overlap and frequently clash. The interpretation of much of the experimental data has been strongly influenced by these theories. Although a number of these differences of opinion have existed for years, an article by Studitsky ('63a) seems to have been the stimulus for a symposium on controversial questions of regeneration held in 1964, at which time these four men presented their views on the nature of the regenerative process (Babaeva and Liosner, '65).

L. V. Polezhaev of the Institute of Animal Morphology in Moscow maintains that regenerative capacity is a fundamental property of living matter, but that during phylogeny and ontogeny there is usually a decline in natural regenerative ability (Polezhaev, '65). Two basic concepts form a framework for much of the research carried out by Polezhaev's school. The first is the necessity for damage in a regenerative process. Polezhaev divides regeneration into two general phases, an early phase of destruction and dedifferentiation and a later phase of differentiation and growth. To him, dedifferentiation of tissues is the key to regeneration and the best way to produce dedifferentiation is by tissue destruction. The second basic concept is that regeneration is dependent upon the "conditions" or milieu (uslovie), not only in the natural loss of regenerative capacity, but also in the experimental restoration of regeneration in tissues and organs. Experiments based upon these premises have provided considerable fundamental information about certain regenerative phenomena and have influenced Western research to a greater extent than other Russian work.

In marked contrast to Polezhaev's position, A. N. Studitsky, also at the Institute of Animal Morphology, believes that natural regenerative capacity in animals actually increases corresponding to the phylogenetic and ontogenic level of the organism (Studitsky, '63a). Supporting evidence for this concept has come from his compara- 
tive investigations of regeneration in bone, muscle and certain skin appendages. Most Soviet workers in regeneration do not think that Studitsky's theory can be applied on a general basis, but these concepts have played a major role in shaping the course and goals of Soviet regeneration research during the past 20 years. Although I do not think that the evidence procured to date allows any general statement to be made concerning the phylogenetic distribution of regenerative powers, Studitsky's work, particularly in muscle regeneration, has brought to light some very striking biological phenomena which merit further attention.

Much of the work carried out in the laboratory of L. D. Liosner of the Institute of Experimental Biology in Moscow concerns restorative phenomena of internal organs (Liosner, '61, '64a). Instead of propounding a general theory of regeneration as Studitsky and Polezhaev have done, Liosner has channeled his efforts more toward the classification of restorative processes, especially those involving internal organs (Liosner, '64b, '65). The most controversial point in his system of classification is the term "regeneration hypertrophy," originally put forth by his late wife, M. A. Vorontsova ('53). By regeneration hypertrophy, Liosner refers to the restoration of mass and functional of an internal organ after injury to that organ. His classification limits compensatory hypertrophy to the enlargement of one member of a paired organ after removal of the other (Liosner, '63). A number of Soviet investigators, notably Polezhaev ('65) and Voitkevich ('65a), deny that regeneration hypertrophy is a true regenerative process. They assert that it is only a case of compensatory or functional hypertrophy and do not include it in their general schemes of regeneration.

A. A. Voitkevich of the Institute of Medical Radiology at Obninsk has dealt mainly with problems of restoration of endocrine organs. He has not formulated a detailed phylogenetic theory, but instead is developing a concept integrating regenerative phenomena in vertebrates with their physiological condition, including reciprocal correlations between a regenerating organ and endocrine glands (Voitkevich, '65a, b). Voitkevich's most controversial position is that regeneration of a number of internal organs, especially the thyroid gland, takes place mainly at the wound surface. This is in direct contradiction to the position of Liosner.

\section{AREAS OF EMPHASIS}

Muscle. One of the more successful areas of research has been the regeneration of skeletal muscle. Most of the early work was done by Studitsky ('59), who found that after certain rather drastic experimental manipulations, striated muscle tissue of birds and mammals shows a surprisingly high restorative capacity. The theoretical basis behind Studitsky's methods of stimulating muscle regeneration is that certain abnormal conditions which disrupt the integrity of muscle tissue with respect to structure, function, nutrient supply and trophic connections cause the muscle tissue to revert to a "plastic condition," from which state the muscle has a greater regenerative capacity than normal healthy muscle. Studitsky makes a distinction between the plastic condition and dedifferentiation, but others (Polyezhaev, '65) think that the two states are identical. In most of their experiments on muscle, Studitsky and his co-workers have produced the plastic condition by means such as mincing portions of muscle and then autotransplanting these pieces back into their original location (Studitsky et al., '56), denervation prior to resection (Striganova, '61, Studitsky et al., '63; Zhenevskaya, '62) and in situ damage prior to resection (Studitsky, '59). The muscles most commonly worked upon have been the biceps brachii in chickens and the gastrocnemius in rats.

During a visit to Studitsky's laboratory, I was shown several examples of muscle regenerates produced by completely removing the gastrocnemius muscle of a rat, finely mincing this tissue and replacing it into the site from which it was removed. These muscles resembled the originals quite closely in form, but Studitsky said that the final size and functional capacity were almost always less than that of the original muscle. In experiments designed to define environmental conditions required for the differentiation of regenerating muscle tissue, Studitsky ('63b) has used the 
methods of chorioallantoic grafting and transplantation and has found that mechanical tension is needed in the late stages of skeletal muscle regeneration, whereas this is not necessary in the case of smooth muscle. An adequate nerve supply has been found to be essential for the later stages of differentiation in the newly regenerated muscle fibers (Zhenevskaya, '62), but as in other regenerating systems, the reason for such dependence upon innervation has not been determined.

This method provides a very useful experimental model for the investigation of certain purely regenerative phenomena. Further study of the development of fairly well proportioned muscles and tendons from a homogeneous mass could possibly lead to a greater knowledge of the factors leading to the morphogenesis of muscle in normal development. Studitsky's basic method of producing muscle regeneration has been repeated and confirmed in my laboratory (Carlson, '67).

Cardiac muscle. In recent years research on regeneration of cardiac muscle has received considerable attention in several laboratories. The most extensive studies have been conducted in the laboratories of L. V. Polezhaev, who has examined reparative phenomena in the heart following injury, mainly thermocoagulation. Attempts at stimulation of regeneration have included the application of substances such as extracts or hydrolysates of muscle, vitamin $B_{12}$ and thyroidin as stimulators of muscle regeneration and other substances (pyrogenol, trypsin, leukocyte serum and spleen extract) as inhibitors of scar tissue formation (Polezhaev et al., '65). While certain combinations of these substances have produced some regeneration of cardiac muscle, no way has yet been found to prevent connective tissue from eventually taking over the damaged area and effectively preventing further regeneration of muscle fibers. Recent work in this laboratory has used diphtheritic myocarditis as a source of heart damage (Kolchin, '66; Polezhaev et al., '66).

A somewhat different approach to research on restoration of heart muscle is being conducted by members of the Medical Institute at Gorky, who along with studies of regeneration in components of the ventricular walls and papillary muscles (Sinitsin, '66), have also done experimental work on revascularization of the ventricles with the help of pedicle grafts of auricular tissue (Amosova, '65).

Although it has been found by these laboratories that cardiac muscle fibers are not totally lacking in the capacity to undergo regenerative changes, it appears that before any major advances can be expected in this area some method will have to be devised to strongly inhibit scar tissue formation while yet maintaining an environment compatible with the continuance of the early regenerative changes taking place in the muscle fibers themselves.

Bone. Research on skull regeneration has provided some very interesting results. Working in Polezhaev's laboratory, Matveeva ('59) has extensively investigated the regeneration of skull defects. The method has been the filling in of large defects with a sawdust made from fresh autograft or homograft material taken from skull or long bones. Lyophilized bone fragments have also been used successfully (Matveeva, '61). Within a few weeks spongy bone is formed in the connective tissue throughout the implant and subsequently plates of bone appear. The presence of dura mater is necessary for this process to occur. This method, called "regeneration by induction" by Polezhaev ('66a), has been successful in 100\% of the cases in dogs. Recently Strebkov ('66) presented a report of the use of this method in 12 cases of human skull defects of up to 9 by $12 \mathrm{~cm}$ in size. Within 12 months there was fairly convincing $x$-ray evidence of the filling in of these defects with an $x$-ray dense material. Of all the Soviet work designed to stimulate regeneration in mammalian tissues and organs, this method seems to have the greatest potential for immediate clinical application.

Internal organs. Although there have been numerous studies on the regeneration of most internal organs, they have been mainly of a descriptive nature, and no major breakthroughs have yet appeared.

Regeneration of the liver has received by far the most attention. Much of the work on liver regeneration has been conducted on a morphological basis, and the histological and cytological findings are gen- 
erally in agreement with those reported elsewhere. Some Soviet authors, however, place considerable emphasis upon amitosis as one of the means for increasing liver mass, especially in the early stages before the first peak of mitotic activity. Most of the Soviet work on liver is well summarized in a monograph by Siderova et al. ('66).

An area receiving considerable emphasis is growth control in the regenerating liver. G. D. Tumanishvili at the Institute of Experimenal Morphology in Tbilisi has shown that extracts of liver from different species exert definite organospecific stimulatory effects upon the regenerating liver, and he has hypothesized that release of certain substances during the destructive phase following wounding may stimulate the subsequent phase of proliferation (Tumanishvili, '60). More recent work (Tumanishvili, '65) has indicated that considerably more complex interactions of tissue products results in a cyclic pattern of growth stimulation. At the Institute of Experimental Biology in Moscow, both Romanova ('66) and Vyazov and associates (personal communication) have been testing concepts of humoral regulation of liver growth by experiments on fetal-maternal systems after partial hepatectomy to the mother.

At the Gorky Medical Institute, Solopaev and associates (Solopaev et al., '66) have been conducting a vigorous research program on regeneration of the liver after the production of experimental cirrhosis, and they have claimed that normalization of structure occurs as a result of regeneration. Solopaev ('66) maintains that intensive regeneration of parenchymatous elements of an organ inhibits the proliferation of connective tissue and may even lead to its resorption.

Rather extensive studies on restoration of lung volume after resection have been conducted by Romanova ('59, '60, '64). She has found that, in the main, restoration of functional lung tissue occurs by increase in alveolar size and by thickening of the septal walls. Recent work (Leikina et al., '66; Romanova, '66) has indicated that a desoxynucleoprotein extracted from lung tissue at the period of maximum DNA synthesis is active in stimlating the formation of increased RNA in lungs undergoing hypertrophy. This effect appears to be organospecific and is not seen in extracts from normal tissue.

Regeneration of other organs such as kidneys, spleen, lymph nodes, stomach, intestines and salivary and lacrimal glands has been studied at the descriptive level, but little information on the mechanisms involved has yet been uncovered. The emphasis of many of these studies has been to indicate a distinction between compensatory hypertrophy and regenerative hypertrophy. Much of this work is summarized in Liosner ('60).

Endocrine glands. Studies on the regeneration of endocrine glands have been carried out in much the same manner as the research previously described for other internal organs. Recently, however, more emphasis has been placed upon the relationships of functional activity of the glands and of the general physiological state of the animal to the regenerative processes in question (Voitkevich, '65b).

Most of the research on regeneration of the thyroid gland has been carried out in the laboratories of A. A. Voitkevich. Voitkevich places great emphasis on the dependence of thyroid regeneration on the physiological condition of the gland (Voitkevich, '65a) and has found that after resection of a large portion of the thyroid, the remaining follicles functionally hypertrophy. Since too great a degree of functional hypertrophy of the follicles does not lend itself well toward regeneration of lost tissue, Voitkevitch has obtained better regeneration of thyroid follicles by supplementing the circulating level of thyroid hormone with exogenous material.

Voitkevich ('62) considers the regeneration of new thyroid tissue to be distinct from the hypertrophic reaction and to occur as outgrowths of new follicles, often in the vicinity of the original wound, which itself is filled in with scar tissue. He thinks that the new follicles may arise from already existing germinative zones in young animals or in newly formed zones in older individuals. Bredikhin ('62) has observed outgrowths of new follicles in pieces of thyroid tissue transplanted into the anterior chamber of the eye. 
Until recent years, regeneration of the pancreas had received comparatively little attention, but at present a number of Soviet laboratories are investigating the regenerative potentials of both the acinar and insular portions. In most experimental animals (mice, rats, guinea pigs and dogs) there seems to be general agreement that restoration of weight in a resected pancreas (30-50\% removal) occurs, but it does not always attain control levels. It is also agreed that acinar mass is restored both by acinar hypertrophy and by proliferative activity, but there is some variation of opinion concerning the location of the areas of regenerative activity. Recent autoradiographic evidence has indicated a surprisingly high uptake of tritiated thymidine by regenerating acinar cells as well as apparent pockets of proliferative activity (Zelenina, '66). The findings on restitution of islet tissue are considerably more nebulous, but along with hypertrophy, some authors have alluded to the formation of islet cells from dedifferentiated cells arising from acinar areas or perivascular tissue (Segida, '62; Klimova, '65). In view of the difficulty of determining the origin and developmental fate of individual cells types in regenerating systems, these studies are provocative, but not definitive.

Regeneration of the ovary remains an undecided issue, especially with regard to the formation of new primary follicles. Despite a number of papers presenting evidence for the formation of new follicles following ovarian resection (Artemieva, '61; Artemieva and Farutina, '62; Kharlova, '58), discussion in a recent Soviet regeneration conference indicated that the matter of ovarian regeneration is still far from solved.

Nervous tissue. Although regeneration in the mammalian central nervous system has not been extensively studied in the Soviet Union, recent work has brought to light some evidence of regenerative phenomena. Polezhaev et al. ('57) removed portions of the cerebral cortex in young kittens, pups and rats and found that some gross and histological restoration of removed tissue did take place. This occurred, however, only in very young animals and depended upon preservation of a part of the neural substrate of the cortex, the presence of meninges and the absence of blood clots and scar tissue from the area of the wound. Without these conditions, regeneration did not occur even in young animals. Similar findings in young puppies have been recorded by others (Ivannikova, '63). Recently Reznikov ('65, '66) has reported the stimulation of amitotic divisions in the cerebral cortex of adult rats by the injection of biogenic stimu. lators such as freshly prepared, highly polymerized RNA or brain homogenate. Such stimulation occurred only if the ma. terial was injected intraventricularly in contrast to negative results after subcu. taneous injection. L. A. Matinyan ('66) has reported a significant restoration of function and structure in rats with completely resected spinal cords after enzyme treatments. A regimen of hyaluronidase followed by trypsin was reported to be most effective. Matinyan indicated that such treatments are being tested in clinical situations. There is evidence that in the future, work on regeneration of the central nervous system will receive more emphasis and that standard histological investigations will be supplemented by techniques such as autoradiography.

Extremities. Emphasis upon regeneration of extremities has declined considerably during the past two decades. Polezhaev has continued his studies on the stimulation of limb regeneration in amphibians. Although he has done some recent work on anurans (Polezhaev, '57), the bulk of work conducted by him and his associates now concerns the restoration of regenerative capacity in irradiated axolotl limbs (Polezhaev, '66b,c). By means of injections of mammalian tissue homogenates, extracts or freshly prepared RNA or by repeated amputation, a large percentage of limbs, having been previously irradiated with 7000-10,000 r, show varying degrees of restoration of regenerative capacity. Of these treatments, RNA injections are particularly effective. Working in the same laboratory, Teplits ('62, '64) and Tuchkova ('64, '65) have provided evidence for a decreased amount and apparent activity of RNA in the irradiated cells and a subsequent increase in limbs stimulated to regenerate. 
Interpretation of these results is made somewhat more difficult by the fact that upon repeated amputation, regeneration is increased in both experimental limbs and in non-irradiated controls. Polezhaev believes that the irradiated cells themselves, acted upon by the substances introduced into the limbs or by products of tissue destruction, make up the greater share of the regenerate. Although several investigators have proposed other mechanisms for the restoration of regenerative capacity to irradiated limbs (Stinson, '64; Trampusch, '64), none of these covers all the experimental conditions, and the mechanism underlying this interesting phenomenon remains open for further clarification.

V. P. Kudokotsev at the A. M. Gorky Kharkov State University has continued an active research program on the stimulation of regeneration of extremities, primarily in lower vertebrates. The chief methods used have been the application of homologous tissue extracts and the deviation of supplementary peripheral nerves to normally nonregenerating limbs (Kudokotsev, '59, '60, '62).

Voitkevich (Woitkevich, '59) has been investigating several populations of frogs (Rana ridibunda and $R$. esculentia) in which substantial numbers (5-30\%) have natural supernumerary hind limbs. Such limbs have never appeared in animals bred in the laboratory, and up to the present the etiology of this condition has not been discovered, but Voitkevich says that it is not traumatic. Such accessory structures are only found on the hind limbs. They have sensory innervation only and if amputated, the regenerates also develop supernumerary structures (Voitkevich, '58). The histology of the amputation surface is not described, however, and interpretation of this report is somewhat difficult. Further clarification of the causative factors in this phenomenon could add considerably to our understanding of the control of limb development and morphogenesis.

Regeneration of irradiated tissues. The restoration of function in irradiated tissues has been a priority subject in many areas of Soviet biomedical research for a number of years, and the field of regenera- tion is no exception. Studies are being conducted on the effect of ionizing radiations on regenerative possibilities in most of the tissues and organs in which regeneration is being studied. Particular emphasis seems to be placed upon nervous tissue, skin and bone. In Samarkand, F. N. Golub and associates are conducting studies on the effects of irradiation on healing processes in adult nerves and bones and are also investigating the healing ability of bones in young mammals irradiated in utero or born from chronically irradiated parents (Britun, '66; Golub and Dokuchaeva, '66). Most of the research in this area so far has consisted of descriptions of the alterations in normal regenerative capacities of irradiated organs, but work on altering the radiosensitivity of tissues or restoring regenerative capacity in already irradiated organs is also being done.

\section{THE PRESENT STATUS OF SOVIET REGENERATION RESEARCH}

The most striking features of current Soviet work in regeneration are the stress on mammalian research, the high degree of organization of this research and the total number of people working on regeneration. The high priority on mammalian research and the relative lack of emphasis placed upon lower vertebrates and invertebrates appears, in part, due to the natural evolution of the earlier work and thought in this field. The strong emphasis on the practical results of research, common to most areas of scientific endeavor in the Soviet Union, has also probably played a significant role in the selection of mammals as research objects. The stress placed upon the restoration of function in irradiated organs, not only with respect to regeneration, but in other areas of biology as well, appears to be another sequel to the emphasis on the practical side of research.

The distribution of research effort in this field is such that the regeneration of almost every tissue and organ in the mammalian body is being studied in one or more laboratories. There is relatively little overlap of research effort, but different aspects of certain complex regenerating systems, such as the liver, are being studied in several laboratories. There is considerable communication among the 
laboratories working in this field, and recently there have been annual all-Union conferences on various aspects of regeneration. Some indication of the amount of regeneration research currently underway in the Soviet Union can be gained by the number of papers presented at recent meetings. In a conference on problems of regeneration and transplantation sponsored by the Medical Institute at Gorky in 1965, 59 papers on regeneration were presented. A more biologically oriented conference on "Conditions of Regeneration of Organs and Tissues in Animals," held in Moscow in 1966 included 78 reports. In the most recent conference, "On the Problem of Regeneration of Pathologically Changed Organs and the Reversibility of Pathological Changes," 90 medically oriented papers were presented.

The type of research performed has, in the past, and will be, in the near future at least, limited to some degree by the availability of certain materials and pieces of equipment. Up to now the number of investigations in which the electron microscope, histochemical or radioisotope techniques have been employed has been relatively small, and despite recent resolutions to the contrary, there seems to be little indication of an immediate increase in the availability of these commodities.

Concerning the Soviet work as a whole, research in some areas has produced outstanding results whereas in others no major advances have yet taken place. Since in the past 20 years there has been relatively little communication between the divergent courses of regeneration research in the Soviet Union and the Western countries, a bit more cross fertilization of ideas would probably benefit both sides.

\section{LITERATURE CITED}

Amosova, V. V. 1965 Revascularization of the myocardium with the help of an auricular transplant on a nutrient flap (Russian). In: Proceedings of the Scientific Conference on the Problem of Regeneration and Transplantation of Organs and Tissues, Gorky, pp. 263267.

Artemieva, N. S. 1961 Regenerative capacity of the rat ovary after compensatory hypertrophy (Russian). Byull. Exp. Biol. Med., 51(1): 80-86.

Artemieva, N. S., and L. M. Farutina 1962 On restorative processes in an ovary subjected to the action of thio-TEF (Russian). Byull. Exp. Biol. Med., 53(1): 98-101.
Babaeva, A. G., and L. D. Liosner 1965 Symposium on controversial questions in the study of regeneration (Russian). Arkh. Anat. Gist. Embryol., 48(1): 103-107.

Bredikhin, T. F. 1962 The efficacy of transplantation of the thyroid gland into the anterior chamber of the eye (Russian). Byull. Exp. Biol. Med., 53(3): 92-96.

Britun, A. I. 1966 Post-traumatic regeneration of bony tissue of young animals subjected to irradiation in the prenatal period of development (Russian). In: Conditions of Regeneration of Organs and Tissues in Animals. Moscow, pp. 25-28.

Carlson, B. M. 1967 An investigation into a method for the stimulation of regeneration. of skeletal muscle (Abstr.). Anat. Rec., 157: 225.

Golub, F. M., and N. F, Dokuchaeva 1966 On reparative regeneration of bony tissues in animals born from chronically irradiated parents (Russian). In: Conditions of Regeneration of Organs and Tissues in Animals. Moscow, pp. 60-63.

Ivannikova, T. V. 1963 The possibility of division of cortical neurons (Russian). Byull. Exp. Biol. Med., 55(1): 93-96.

Kharlova, G. V, 1958 Regeneration of the ovary in white rats following the ligation of its neurovascular bundle (Russian). Doklady Akad. Nauk SSSR, 120: 669-672.

Khruschev, G. K. 1954 Introduction to Problems of Restoration of Organs and Tissues of Vertebrates (Russian). Trudy Inst. Morph. Zhivotnikh im. A. N. Severtsova, 11: 3-5.

Klimova, E. I. 1965 On the question of morphological study of reparative regeneration of the rat pancreas (Russian). In: Proceedings of the Scientific Conference on the Problem of Regeneration and Transplantation of Organs and Tissues. Gorky, pp. 191-195.

Kolchin, S. P. 1966 Contractile function of the myocardium in diphtheritic myocarditis and in stimulation of regeneration (Russian). In: Conditions of Regeneration of Organs and Tissues in Animals. Moscow, pp. 122-126.

Kudokotsev, V. P. 1959 Regeneration of the limbs in the desert snake-eyed skink (Ablepharus deserti) (Russian). Doklady Akad. Nauk SSSR, 126: 1141-1144.

1960 Stimulation of the regeneration of extremities in acaudate amphibia by the action of tissue extract (Russian). Doklady Akad. Nauk SSSR, 132: 715-718.

1962 Stimulation of the regenerative process in the extremities of lizards by the method of supplementary innervation (Russian). Doklady Akad. Nauk SSSR, 142: 233236.

Leikina, E. M., L. K. Romanova and K. K. Antipova 1966 Investigation of the biological activity of a desoxyribonucleoprotide, isolated from lung tissue undergoing compensatory hypertrophy (Russian). In: Conditions of Regeneration of Organs and Tissues in Animals. Moscow, pp. 154-158.

Liosner, L. D. 1960 Regeneration of Organs in Mammals (Russian). Medgiz, Moscow, 392 pp. 
1961 Research report 1957-1960 of the Laboratory for Growth and Development. Folia Biol. (Praha), 7: 285-294.

1963 Compensatory Hypertrophy of Organs in Mammals and in Man (Russian). Izdatel. Med. Lit., Moscow, 318 pp.

1964a Research report 1961-1963 of the Laboratory for Growth and Development. Folia Biol. (Praha), 10: 472-479.

1964b A contribution to the classification of regenerative processes (Russian). In: Regeneration and Cell Division in Animals. Eds. L. D. Liosner and V. N. Dobrokhotov. Izdatel. Nauka, Moscow, pp. 7-20.

1965 Regeneration hypertrophy as one of the fundamental means of restoration of organs (Russian). Arkh. Anat. Gist. Embryol., 48(1): 96-102.

Matinyan, L. A. 1966 Electrophysiological, structural and histochemical picture of the completely resected spinal cord with the use of enzymes (Russian). In: Conditions of Regeneration of Organs and Tissues in Animals. Moscow, pp. 177-181.

Matveeva, A. I. 1959 Regeneration of the cranial vault in dogs by the method of destruction (Russian). Folia Biol. (Warsaw), 7: 239-257.

- 1961 Regeneration of the cranial vault in dogs after transplantation of lyophilized bone shavings and dura mater (Russian). Doklady Akad. Nauk SSSR, 138: 239-242.

Polezaiev, L. W., and W. N. Faworina 1935 tuber die Rolle des Epithels in den anfänglichen Entwicklungsstadien einer Regenerationsanlage der Extremität beim Axolotl. Arch. f. Entwmech., 133: 701-727.

Polezhaev, L. V. 1945 Fundamentals of the Developmental Mechanics of Vertebrates (Russian). Izdatel. Akad. Nauk SSSR, Moscow, $287 \mathrm{pp}$.

1946a D. P. Filatov (1876-1943) as a scientist and his role in developmental mechanics (Russian). Zh. Obsch. Biol., 7: 313344.

$1946 \mathrm{~b}$ The loss and restoration of regenerative capacity in the limbs of tailless amphibia. Biol. Revs., 21: 141-147.

1957 Changes in the regenerative capacity and immunity during the ontogeny of tailless amphibians (Russian). Doklady Akad. Nauk SSSR, 113: 702-705.

- 1965 The law of alternation of regenerative capacities of organs in animals (Russian). Arkh. Anat. Gist. Embryol., 48(2): 67-74.

1966a Regeneration by induction (Russian). Zh. Obsch. Biol., 27: 223-232.

- $1966 \mathrm{~b}$ Restoration of regenerative capacity, lost by roentgen irradiation (Russian). Izvestia Akad. Nauk SSSR, Ser. Biol., No. 1: 37-58.

$1966 \mathrm{c}$ Mechanism of restoration of regenerative capacities, suppressed by roentgen irradiation (Russian). Izvestia Akad. Nauk SSSR, Ser. Biol., No. 2: 254-265.

Polezhaev, L. V., L. B. Akhabadze, N. A. Muzlaeva and M. P. Yavich 1965 Stimulation of Re- generation of Cardiac Muscle (Russian). Izdatel. Nauka, Moscow, 396 pp.

Polezhaev, L. V., S. P. Kolchin and I. E. Sadokova 1966 Stimulation of regeneration of cardiac muscle damaged by diphtheria (Russian). In: Conditions of Regeneration of Organs and Tissues in Animals. Moscow, pp. 192-196.

Polezhaev, L. V., A. I. Matveeva and N. A. Zakharova 1957 Regeneration of removed parts of cerebral hemispheres in mammals (Russian). Doklady Akad. Nauk SSSR, 113: $472-475$.

Reznikov, K. Yu. 1965 A quantitative method of estimating the stimulation of division of nerve cells in the cerebral cortex of the rat (Russian). Doklady Akad. Nauk SSSR, 164: 187-190.

Reznikov, K. Yu, and V. M. Kondik 1966 Concerning the possibility of stimulation of physiological regeneration of nervous tissue of the cerebral cortex in the rat by injecting certain biostimulators into the fourth ventricle of the brain (Russian). In: Conditions of Regeneration of Organs and Tissues in Animals. Moscow, pp. 231-235.

Romanova, L. K. 1959 The regenerative power of the hypertrophied lung of the crested triton (Russian). Byull. Exp. Biol. Med., 47(3): 89-93. 1960 Regenerative hypertrophy of the lungs in rats after one-stage removal of the entire left lung and the diaphragmatic lobe of the right lung (Russian). Byull. Exp. Biol. Med., 50(11): 100-105.

- 1964 Reparative processes in the lungs of Bombina (Russian). In: Regeneration and Cell Division in Animals. Eds. L. D. Liosner and V. N. Dobrokhotov, Izdatel. Nauka, Moscow, pp. 124-142.

1966 The manifestation of humoral factors regulating regenerative and compensatory hypertrophy of internal organs (Russian). In: Conditions of Regeneration of Organs and Tissues in Animals. Moscow, pp. 236-240.

Segida, G. V. 1962 Regenerative hypertrophy of the pancreas in guinea pigs (Russian). Byull. Exp. Biol. Med., 54(11): 88-91.

Siderova, V. F., Z. A. Ryabinina and E. M. Leikina 1966 Regeneration of the Liver in Mammals (Russian). Izdatel. Meditsina, Leningrad, $205 \mathrm{pp}$.

Sinitsin, N. P. 1966 The participation of papillary muscles in the process of regeneration of the muscular tissue of the ventricular wall of the heart (Russian). In: Conditions of Regeneration of Organs and Tissues in Animals. Moscow, pp. 262-266.

Solopaev, B. P. 1966 Concerning the tissue interactions in processes of reparative regeneration of pathologically changed organs and the reversibility of pathological changes (Russian). In: Conditions of Regeneration of Organs and Tissues in Animals. Moscow, pp. 266-270.

Solopaev, B. P., Yu. P. Butenov and G. G. Kuznetsova 1961 Reparative regeneration of the liver with experimentally induced cirrhosis (Russian). Byull. Exp. Biol. Med., 51(1): 74-79.

Stinson, B. D. 1964 The response of $\mathrm{x}$-irradiated limbs of adult urodeles to normal tissue 
grafts. IV. Comparative effects of autografts and homografts of complete forearm regenerates. J. Exp. Zool., 157: 159-178.

Strebkov, V. S. 1966 An experiment on the application of the method of destruction of L. V. Polezhaev with the aim of regeneration of bone in regions of the cranial vault (Russian). In: Conditions of Regeneration of Organs and Tissues in Animals. Moscow, pp. 277-281.

Striganova, A. R. 1961 Reactivity and Restorative Capacity of Denervated Muscle in Various Stage of Atrophy (Russian). Izdatel. Akad. Nauk SSSR, Moscow, 147 pp.

Studitsky, A. N. 1948 Current Problems in Regeneration. Izdatel. Pravda, $32 \mathrm{pp}$.

- 1959 Experimental Surgery of Muscles (Russian). Izdatel. Akad. Nauk, Moscow, 338 pp.

- 1963a Controversial questions in the current field of regeneration (Russian). Zh. Obsch. Biol., 24: 241-260.

- 1963b Dynamics of the development of myogenic tissue under conditions of explanation and transplantation. In: Cinemicrography in Cell Biology. G. G. Rose, ed. Academic Press, N. Y., pp. 171-200.

Studitsky, A. N., R. P. Zhenevskaya and O. N. Rumiantseva 1956 Fundamentals of the technique of restoration of muscle by means of transplantation of minced muscle tissue (Russian). Cesk. Morfol, 4: 331-340.

- 1963 The role of neurotrophic influences upon the restitution of structure and function of regenerating muscles. In: The Effect of Use and Disuse on Neuromuscular Functions. B. Gutmann and P. Hnik, eds. Prague, pp. 71-81.

Teplits, N. A. 1962 Changes in the content of nucleic acids in axolotl limbs after roentgen irradiation and after restoration of regenerative capacity (Russian). Doklady Akad. Nauk SSSR, 147: 244-247.

1964 Changes in the content of nucleic acids in axolotl limb tissues after their roentgen irradiation and in normal regeneration (Russian). Doklady Akad. Nauk SSSR, 149: $442-445$.

Trampusch, H. A. L. 1964 Nerves as morphogenetic mediators in regeneration. In: Mechanisms of Neural Regeneration. M. Singer and J. P. Schade, eds. Elsevier, Amsterdam, pp. 214-217.
Tuchkova, S. Ya. 1964 Changes in nucleic acid content during inhibition of regeneration of axolotl limbs after roentgen irradiation (Russian). Doklady Akad. Nauk SSSR, 159: 215-218.

- 1965 Histological and histochemical investigation of the restoration of regenerative capacity of axolotl limbs, inhibited by roentgen irradiation (Russian). Radiobiologica, 5: 207-210.

Tumanishvili, G. D. 1960 Stimulating action of tissue extracts on regenerative processes. J. Embryol. Exp. Morph., 8: 226-238.

1965 The role of cellular interrelationships in the regulation of tissue growth (Russian). In: Cellular Differentiation and Induction Mechanisms. G. V. Lopashov, A. A. Neifach and O. G. Stroeva, eds. Izdatel. Nauka, Moscow, pp. 204-219.

Umanski, E. E. 1937 Investigation of the regenerative process by the method of excluding isolated tissues from roentgen rays (Russian). Biol. Zhurn., 6: 739-758.

Voitkevich, A. A. 1958 Regeneration of additional extremities in frog larvae (Russian). Byull. Exp. Biol. Med., No. 6: 100-104.

1962 Modes of regeneration of the thyroid gland (Russian). Doklady Akad. Nauk SSSR, 147: 977-980.

1965a Conditions of regeneration of endocrine organs (Russian). Arkh. Anat. Gist. Embryol., 48(e): 111-120. 1965b Restorative Processes and Hormones (Russian). Izdatel. Meditsina, Leningrad, 252 pp.

Vorontsova, M. A. 1949 Regeneration of Organs in Animals (Russian). Sovietskaya Nauka, Moscow, 270 pp.

- 1953 Restoration of Lost Organs in Animals and Man (Russian). Sovietskaya Nauka, Moscow, 122 pp.

Vorontsova, M. A., and L. D. Liosner 1960 Asexual Propagation and Regeneration. Pergamon, N. Y., $489 \mathrm{pp}$.

Woitkevich, A. A. 1959 Natürliche Mehrfachbildungen an Froschextremitäten. G. Fisher Verlag, Jena.

Zelenina, I. A. 1966 Autoradiographic investigation of DNA metabolism in the regenerating pancreas (Russian). In: Conditions of Regeneration of Organs and Tissues in Animals. Moscow, pp. 89-92.

Zhenevskaya, R. P. 1962 Experimental histologic investigation of striated muscle tissue. Rev. Canad. Biol., 21: 457-470. 